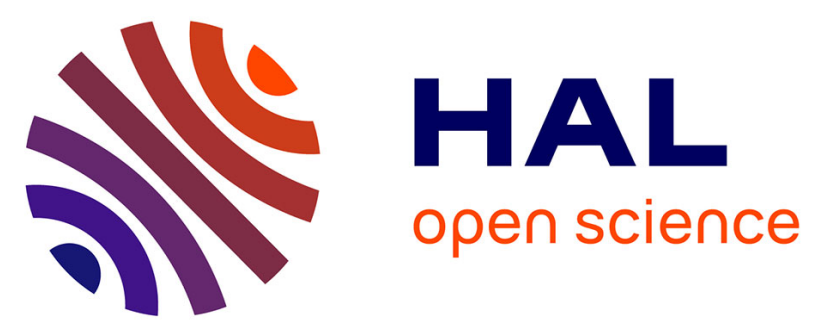

\title{
Lipid binding to cytoglobin leads to a change in heme coordination: a role for cytoglobin in lipid signalling of oxidative stress
}

\author{
Brandon J Reeder, Dimitri Svistunenko, Mt Wilson
}

\section{- To cite this version:}

Brandon J Reeder, Dimitri Svistunenko, Mt Wilson. Lipid binding to cytoglobin leads to a change in heme coordination: a role for cytoglobin in lipid signalling of oxidative stress. Biochemical Journal, 2011, 434 (3), pp.483-492. 10.1042/BJ20101136 . hal-00569401

\author{
HAL Id: hal-00569401 \\ https://hal.science/hal-00569401
}

Submitted on 25 Feb 2011

HAL is a multi-disciplinary open access archive for the deposit and dissemination of scientific research documents, whether they are published or not. The documents may come from teaching and research institutions in France or abroad, or from public or private research centers.
L'archive ouverte pluridisciplinaire $\mathbf{H A L}$, est destinée au dépôt et à la diffusion de documents scientifiques de niveau recherche, publiés ou non, émanant des établissements d'enseignement et de recherche français ou étrangers, des laboratoires publics ou privés. 


\section{Lipid binding to cytoglobin leads to a change in heme coordination: a role for cytoglobin in lipid signalling of oxidative stress}

Brandon J. Reeder ${ }^{*}$, Dimitri A. Svistunenko and Michael T. Wilson

Department of Biological Sciences, University of Essex, Wivenhoe Park, Colchester, Essex, CO4 3SQ, UK.

Classification: Biological Sciences, Biochemistry

Corresponding Author:

Dr. Brandon J. Reeder,

Department of Biological Sciences,

University of Essex,

Wivenhoe Park,

Colchester,

Essex, CO4 3SQ,

UK.

Tel: $+44(0) 1206872119$

Fax: $+44(0) 1206872592$

email: reedb@essex.ac.uk

Keywords: cytoglobin, lipids, cell signalling, hemoglobins, peroxidase, redox sensor 


\section{Synopsis}

Cytoglobin is a recently discovered hexacoordinate hemoglobin that does not appear to function as a classical oxygen binding protein. Its function is unknown and studies on the effects of changes in its expression have not decisively determined its role within the cell. We report that the protein is transformed from hexacoordinate to pentacoordinate on binding a lipid molecule. This transformation occurs with the ferric oxidation state of the protein, but not the ferrous state, indicating that this process only occurs under an oxidative environment and may thus be related to redox-liked cell signalling mechanisms. Oleate binds to the protein in a 1:1 stoichiometry and with high affinity $\left(K_{D}=0.7 \mu \mathrm{M}\right)$, however stopped-flow kinetic measurements yield a $K_{D}$ value of $110 \mu \mathrm{M}$. The discrepancy between these $K_{D}$ values may be rationalised by recognising that cytoglobin is a disulfide linked dimer and invoking cooperativity in oleate binding. The lipid-induced transformation of cytoglobin from hexacoordinate to pentacoordinate does not occur with similar hexacoordinate hemoglobins such as neuroglobin, and therefore appears to be a unique property of cytoglobin amongst the hemoglobin superfamily. The lipid-derived transformation may explain why cytoglobin has enhanced peroxidatic activity, converting lipids to various oxidised products, a property virtually absent from neuroglobin and much decreased in myoglobin. We propose that the binding of ferric cytoglobin to lipids and their subsequent transformation may be integral to the physiological function of cytoglobin, generating cell signalling lipid molecules under an oxidative environment.

\section{Introduction.}

Cytoglobin (Cygb) is a recent addition to the hemoglobin super-family. This low abundance protein is ubiquitously expressed in vertebrate tissues, but found in higher concentrations in the brain, eyes, liver, heart and skeletal muscle [1, 2]. Unlike hemoglobin $(\mathrm{Hb})$ and myoglobin $(\mathrm{Mb})$ where the heme iron is pentacoordinate, the ferrous and ferric oxidation states of Cygb are hexacoordinate with both proximal and distal histidine occupying the $5^{\text {th }}$ and $6^{\text {th }}$ coordination sites of the heme iron in the absence of exogenous ligands [3]. This hexacoordinate configuration of the heme iron is also observed with neuroglobin and non-symbiotic plant hemoglobins [4, 5]. Previously known as histoglobin and stellate cell activation-associated protein, Cygb is capable of reversibly binding oxygen and has an affinity for oxygen comparable to $\mathrm{Mb}$ [6]. Thus the function of Cygb has been assumed by some to facilitate oxygen transport to mitochondrial respiratory chain $[1,7,8]$. However, Cygb is present in low concentrations in cells that are not generally associated with particular high metabolic rates and thus oxygen consumption (unlike Mb). Therefore, the proposed role of Cygb in facilitating oxygen diffusion to the respiratory chain of the mitochondria seems unlikely [9]. There have been many alternative suggestions for the in vivo function of this protein. It has been proposed that Cygb may function as an NO dioxgenase, due to its rapid reaction with NO and its upregulation in $\mathrm{Mb}$-free amphibians, suggesting that it may function as an important NO sink in the vascular wall [10]. However, like the oxygen diffusion hypothesis, the low abundance of the protein in most cells casts doubt on Cygb acting as a cell protectant against compounds such as NO or hydrogen peroxide.

The main function of Cygb thus remains unclear. It has been observed, however, that hydrogen peroxide induces Cygb upregulation [11]. This change in expression was not observed with other stresses including heat stress, high osmolarity and UV radiation. Cygb has been reported to have no appreciable catalase activity [7], but has considerable peroxidatic activity, consuming both hydrogen peroxide and lipid peroxides [7, 12]. Cygb knock-down neuroblastoma cells exacerbated cell death upon treatment with hydrogen peroxide, suggesting a role for protection against oxidative stress [11], perhaps as reactive oxygen scavengers [13]. Cygb may play a role in fibrotic organ disorder as it is up-regulated in fibrotic lesions of the pancreas and kidney with overexpression of Cygb in NIH 3T3 fibroblast cells inducing a decrease in migratory activities and increase the expression of collagen mRNA [14]. Cygb expression has also been reported to be involved with 
tumour suppression, with hypoxic cancers significantly up-regulating Cygb [15]. Thus expression of Cygb may also provide a new target for therapy of cancer [12].

The gene and protein expression studies have correlated Cygb up-regulation with functions that may be linked to protection of cells against oxidative stress, perhaps through the redox chemistry of Cygb. However, the biochemical mechanism of Cygb cellular protection remains unknown. Our investigations of Cygb reveal a plausible mechanism through which such protection may be afforded. We report here that ferric Cygb, but not ferrous, undergoes a conformational transition from hexacoordinate to pentacoordinate heme on binding, with high affinity, one lipid molecule per Cygb. This conformational change induced in Cygb at low lipid concentration appears to be a unique function amongst the hemoglobin superfamily. We propose, under an oxidative environment, the protein will be oxidised to the ferric form, allowing interactions with lipid and the opening of the heme pocket to facilitate redox chemistry that catalyses the oxidization of the lipid. Many products of lipid oxidization have known cell signalling functions such as isoprostanes [16-19] or electrophilic lipids [20-23]. Therefore, even though the function of this protein appears to be substantially pro-oxidant, the low concentration of this protein facilitates cell signalling processes that may allow the cell to up-regulate antioxidant defences before extensive oxidative damage occurs or potentially to induce apoptosis if the balance of oxidative chemistry cannot be maintained.

\section{Experimental}

\section{Cytoglobin Engineering and expression.}

The gene for human Cygb was purchased from OriGene (via Cambridge Bioscience, Cambridge, UK), the gene was contained in a PCMV6-AC cloning vector. To facilitate protein expression and purification the gene was sub-cloned from the cloning vector into a pET28a expression vector (Merck, Nottingham, UK) following insertion of a restriction site (FAQ 1). The protein lead sequence contained a Thrombin cleavable His ${ }_{6}$-Tag (MetGlySerSer-6xHis- SerSerGlyLeuValProArgGlySer, with thrombin recognition site shown underlined). At each stage the plasmid DNA sequence was confirmed by GATC-biotech (Konstanz, Germany or London, UK). Vector was transformed into XL1B cells or BL21 DE3 cells (Agilent-Stratagene, Stockport, UK) for cloning or protein expression respectively. Transformation was achieved using the heat shock method.

For protein expression E. coli was added to Luria Bertani medium (10g tryptone, $10 \mathrm{~g}$ sodium chloride and $5 \mathrm{~g}$ yeast extract per I) containing kanamycin $\left(50 \mu \mathrm{g} \mathrm{ml}^{-1}\right)$, shaken at $120 \mathrm{rpm} 37^{\circ} \mathrm{C}$. When optical density was 0.8 at $600 \mathrm{~nm}$ IPTG $(1 \mathrm{mM})$, 5-aminolevulinic acid $(500 \mu \mathrm{M})$ and ferric citrate $(100 \mu \mathrm{M})$ were added to the broth. Carbon monoxide gas was bubbled through the solution for 2 min and the flasks were sealed and incubated for a further 18-24 hrs [24]. Cells were isolated by centrifugation (15000 g) and cells were lysed using an Avestin Emulsiflex C5 homogeniser. His-tagged Cygb was purified using a His-Tag nickel affinity column (GE Healthcare, Amersham, UK) as per manufacturer instructions. Imidazole was removed through dialysis and the His-tag cleaved through incubation with bovine thrombin (Sigma-Aldrich, Poole, UK, $10 \mathrm{U}$ per $\mathrm{mg}$ protein) at room temperature overnight with gentle mixing. His-Tag free protein was purified using the nickel affinity column and the thrombin separated from the cytoglobin by precipitating the thrombin at $\mathrm{pH} 5.0$ (sodium acetate buffer). Thrombin was discarded after centrifugation (4000 g for $10 \mathrm{~min}$ ) and the Cygb filtered through a vivascience vivaspin filter (100 kDa MWCO) to remove trace bacterial catalases, dialyzed and concentrated using a vivaspin or vivacell filter (5 kDa MWCO).

\section{Optical and stopped flow spectroscopy.}

Optical spectra were taken using a Varian Cary 5E UV-Vis-NIR spectrophotometer. Sodium oleate (Sigma-Aldrich, Poole, UK) was dissolved in water to a concentration of $50 \mathrm{mM}$ with gentle warming to ensure complete dissolution. Oleate was diluted in water and titrated $(5 \mu \mathrm{l}$ aliquots, giving $\sim 0.5$ $\mu \mathrm{M}$ final concentration) into cytoglobin $(5 \mu \mathrm{M})$ in $50 \mathrm{mM}$ sodium phosphate buffer $\mathrm{pH} 7.4$ and optical readings taken following each addition. Cardiolipin (Sigma-Aldrich, Poole, UK) was dissolved in ethanol and added to cytoglobin in $20 \mathrm{mM}$ HEPES buffer $\mathrm{pH}$ 7.4. Stopped flow absorbance spectroscopy was used to measure the kinetics of change in heme iron coordination using an 
Applied Photophysics SX20 stopped flow fitted with both a single wavelength photomultiplier and a diode array spectrometer. Cytoglobin (10 $\mu \mathrm{M}$ in $50 \mathrm{mM}$ sodium phosphate buffer $\mathrm{pH} 7.4)$ was rapidly mixed with oleate $(0-2000 \mu \mathrm{M}$ in $50 \mathrm{mM}$ sodium phosphate buffer $\mathrm{pH} 7.4)$ to give final concentrations of one half their original concentration.

\section{Liposome preparation and measurement of lipid oxidation.}

Soybean phospholipids (50 mg, lecithin "asolectin", $19 \%$ phosphatidylcholine, Sigma-Aldrich, type II$\mathrm{S}$ P-5638) was suspended in $10 \mathrm{ml} 25 \mathrm{mM}$ sodium phosphate buffer pH 7.4 containing $25 \mu \mathrm{M}$ diethylenetriaminepentaacetic acid (DTPA) and the solution sonicated in a water bath for $10 \mathrm{~min}$. Further sonification was used if lumps of lecithin were still present. Small unilamellar liposomes were formed from the sonicated solution using a Northern Lipids stainless steel extruder fitted with a Whatman nucleopore drain disk $(25 \mathrm{~mm}$ diameter) and two layers of Whatman nucleopore polycarbonate membranes ( $25 \mathrm{~mm}$ diameter with $0.1 \mu \mathrm{m}$ pore size) as previously described [25]. Liposomes were stored at $4{ }^{\circ} \mathrm{C}$ and used within $2 \mathrm{hrs}$ of preparation.

An Agilent 8453 diode array spectrophotometer was used to measure the oxidation of liposomes. Ferric Mb or Cygb was incubated with the liposomes $(200 \mu \mathrm{g} / \mathrm{mL})$ at $25^{\circ} \mathrm{C}$ at pH $7.4(25 \mathrm{mM}$ sodium phosphate containing $25 \mu \mathrm{M}$ DTPA). Oxidation of liposomes was measured by the appearance of lipid-based conjugated dienes measured optically at $234 \mathrm{~nm}$. To correct for changes in light scattering, a three-point baseline drop was calculated from optical measurements taken at 220, 234, and $250 \mathrm{~nm}$. The lipid hydroperoxide HPODE $\varepsilon_{234 \mathrm{~nm}}=2.5 \times 10^{4} \mathrm{M}^{-1} \mathrm{~cm}^{-1}$ [26] was used to calculate the extinction coefficient using the above method $\left.\varepsilon_{234 \mathrm{~nm}}=1.1 \times 10^{4} \mathrm{M}^{-1} \mathrm{~cm}^{-1}\right)$.

Reverse-Phase HPLC.

Samples were analyzed on an Agilent HP1100 HPLC fitted with a diode array spectrophotometer. The column used was a Zorbax StableBond 300 C3 $250 \mathrm{~mm} \times 4.6 \mathrm{~mm}$ fitted with a $12 \mathrm{~mm} \times 4.6 \mathrm{~mm}$ guard column. Solvents were (A) $0.1 \%$ trifluoroacetic acid (TFA) and (B) acetonitrile containing $0.1 \%$ TFA. The gradient was initially $35 \%$ solvent $B$, stable for 10 min, increasing to $37 \%$ solvent $B$ over 5 min. This was increased to $40 \%$ solvent $B$ over 1 min and then to $43 \%$ solvent $B$ over $10 \mathrm{~min}$. The flow rate was $1 \mathrm{ml} \mathrm{min}^{-1}$, and the temperature was $25^{\circ} \mathrm{C}$.

\section{Standard and Concerted model of lipid binding to cytoglobin.}

Addition of lipids such as oleate and cardiolipin appear to follow a standard classic fractional saturation binding curve that can be described by the equation (1) below:

$\mathrm{Y}=\frac{\left(\left[\mathrm{P}_{\mathrm{T}}\right]+[\mathrm{S}]+\frac{1}{\mathrm{~K}}\right)-\sqrt{\left(\left[\mathrm{P}_{\mathrm{T}}\right]+[\mathrm{S}]+\frac{1}{\mathrm{~K}}\right)^{2}-4\left(\left[\mathrm{P}_{\mathrm{T}}\right][\mathrm{S}]\right)}}{2\left[\mathrm{P}_{\mathrm{T}}\right]} \quad$.......Equation 1

Where $\left[\mathrm{P}_{\mathrm{T}}\right]$ is the total protein concentration, $[\mathrm{S}]$ is the substrate concentration (oleate) and $\mathrm{K}$ is the binding constant. Data was fitted to equations using the least squares method by either Microsoft Excel solver program or Originlab Origin.

However, the lipid binding data may also be fitted to the concerted model, previously devolved for the allosteric binding of oxygen to hemoglobin [27]. The equation to fit the binding curve of a cooperative protein is given below:

$$
Y=\frac{\alpha(1+\alpha)^{n-1}+L c \alpha(1+c \alpha)^{n-1}}{(1+\alpha)^{n}+L(1+c \alpha)^{n}}
$$

.....Equation 2

Where $\mathrm{n}=$ number of subunits, $c=\frac{K_{R}}{K_{T}}, L=\frac{\left[T_{0}\right]}{\left[R_{0}\right]}$ and $\alpha=\frac{[X]}{K_{R}}$. $\mathrm{K}_{\mathrm{R}}$ represents the affinity for lipid in the high affinity $R$ state, $K_{T}$ represents the affinity for lipid in the low affinity $T$ state, $\left[T_{0}\right]$ represents the concentration of protein in the $T$ state in the absence of ligand, $\left[R_{0}\right]$ represents the concentration of protein in the $\mathrm{R}$ state in the absence of ligand and $[\mathrm{X}]$ represents lipid concentration. Using the following values, the concerted model curve in Figure S1 was generated: $n=2, c=0.005882$ and $\mathrm{L}=5340$.

Electron Paramagnetic Resonance.

Cygb $(80 \mu \mathrm{M})$ with or without sodium oleate $(160 \mu \mathrm{M})$ was transferred $(250 \mu \mathrm{l})$ to Wilmad SQ EPR 
tubes (Wilmad Glass, Buena, NJ). Tubes were flash-frozen in dry ice-cooled methanol. Frozen samples were transferred to liquid nitrogen $(77 \mathrm{~K})$ where they were stored prior to measurements.

All EPR spectra were measured using a Bruker EMX EPR spectrometer (X-band) equipped with a spherical high quality resonator SP9703 and an Oxford Instruments liquid helium system as previously described [28]. The modulation frequency was $100 \mathrm{kHz}$. Accurate g values were obtained using the built-in microwave frequency counter and a 2,2-diphenyl-1-picrylhydrazyl powder standard, the $g$ value for which is $g=2.0037 \pm 0.0002$ [29]. The EPR spectra of the blank samples (frozen water) were subtracted from the EPR spectra of the protein samples to eliminate the base line caused by the walls of the resonator, quartz insert, or quartz EPR tube. Relative concentrations of the high spin (HS) and low spin (LS) ferric heme forms in Cygb were estimated from the intensity of the HS ferric heme signal which has been compared to a horse metMb standard sample stored at $77 \mathrm{~K}$. The concentration of the HS ferric haem form in the standard sample has been previously accurately determined as described previously [30]. The comparison was possible due to close lineshapes of the EPR signals of the HS ferric heme forms in Cygb and horse Mb.

\section{Results and discussion.}

\section{Cytoglobin expression in Escherichia coli induces catalase expression}

It has been reported that under aerobic conditions the expression of Cygb in Escherichia coli produces a 'pine-green' coloured protein [24]. Under the hypoxic conditions we employed (bubbling argon gas to partially deoxygenate the culture) the protein produced was also green in colour (see Supplementary Figure S2). Analysis by HPLC showed that this colour is due to significant incorporation of green $d$-type 'chlorin' heme into Cygb in place of the red $b$-type heme (Feprotoporphyrin-IX, see Supplementary Figure S3). In addition there was significant contamination of the Cygb preparation with bacterial catalase (which contains $d$-heme) that necessitated further purification of the protein to remove catalase activity. This catalase production did not occur to any significant extent under identical conditions with the same expression vector expressing Mb instead of Cygb. Thus it appears that the expression of Cygb by E. coli is accompanied by extensive catalase production, resulting in the presence of $d$-type hemes that are acquired by the apo form of Cygb to generate the 'green' or 'pine-green' coloration. It is known that adding $\mathrm{CO}$ to the culture prior to induction of protein expression prevents this problem [24]. We show that adding CO results in Cygb essentially only incorporating $b$-type red heme. Our interpretation is that CO strongly stabilises the protein as the ferrous- $\mathrm{CO}$ form and prevents its redox activity. This conclusion suggests that redox activity plays a role in the cell signalling pathways, inducing up-regulation of catalase production by the bacteria. This is in keeping with our proposal that Cygb functions as a cell-signalling protein.

\section{Optical changes and kinetics of lipid binding to cytoglobin.}

The optical spectrum for Cygb in the ferric oxidation state is essentially identical to that previously described (8) and has a Soret $(\gamma)$ band at $416 \mathrm{~nm}$ and $\beta$ and $\alpha$ bands in the visible region of the spectrum at 535 and $565 \mathrm{~nm}$ respectively, showing the heme iron in a low spin (LS) HisF8-Fe'II-HisE7 coordination. Figure $1 \mathrm{~A}$ and $1 \mathrm{~B}$ show the optical changes induced by oleate binding to ferric Cygb. The binding of oleate creates a hypsochromic shift of the Soret peak from $416 \mathrm{~nm}$ to $412 \mathrm{~nm}$ accompanied with a slight decrease in intensity. The visible peaks are also decreased in intensity as oleate concentration increases, with the appearance of a peak at around $620 \mathrm{~nm}$. The latter is consistent with the formation of a high-spin (HS) pentacoordinate ferric iron, similar to $\mathrm{Mb}$ or $\mathrm{Hb}$, and indicative of water in the $6^{\text {th }}$ coordination site of the iron [31].

The optical changes of ferric Cygb are plotted as a function of oleate concentration in Figure 2A. Addition of oleate appears to follow a classic single site binding curve that can be described by Equation 1 given in the experimental section. The best fit to the data points yields a binding dissociation constant $\left(\mathrm{K}_{\mathrm{D}}\right)$ of $0.70 \mu \mathrm{M}$ and the total protein concentration $\left[\mathrm{P}_{\mathrm{T}}\right]$ of $4.5 \mu \mathrm{M}$, close to the calculated protein concentration of $5 \mu \mathrm{M}$ as measured by optical spectroscopy. Thus the stoichiometry of oleate binding to Cygb is essentially one to one. Figure 2B shows the dependence of 
the pseudo first order rate constant, $k_{\mathrm{obs}}$, as a function of oleate concentration, measured by stopped-flow spectrophotometer. This linear relationship is consistent with a simple mechanism and can be described as in Equation 3:

$$
k_{\text {obs }}=k_{\text {on }}[\text { Oleate }]+k_{\text {off }} \quad \ldots . . \text { Equation } 3
$$

Where $k_{\text {on }}$ and $k_{\text {off }}$ are the association and dissociation rate constants respectively. Thus the slope of the graph gives the $k_{\text {on }}$ value, calculated to be $4.53 \times 10^{4} \pm 8.58 \times 10^{2} \mathrm{M}^{-1} \mathrm{~s}^{-1}$ and the intercept at [oleate] $=0$ gives the value of $k_{\text {off }}$, determined as $5.0 \pm 0.32 \mathrm{~s}^{-1}$, giving a $K_{D}$ value of around $110 \mu \mathrm{M}$.

Oleate is not the only lipid to induce optical changes to Cygb upon binding, cardiolipin also binds to Cygb, resulting in a transformation of the heme iron coordination (see Supplementary Figure S3). The titration also shows identical optical changes that were observed in the presence of oleate (data not shown) and follows classical binding as described in Equation 1 (experimental section). Also, like oleate, the binding stoichiometry of cardiolipin to Cygb is almost one to one with a calculated total protein concentration of $6.8 \mu \mathrm{M}$, compared to the actual protein concentration of $5 \mu \mathrm{M}$ (thus giving 1:1.4 stoichiometry of protein to cardiolipin). The binding dissociation constant was calculated as $0.64 \mu \mathrm{M}$, virtually identical to the $K_{D}$ for oleate binding (Figure $2 \mathrm{~A}$ ).

The binding of oleate to Cygb appears, from Figures 1 and 2, to occur by a simple mechanism. However, the kinetics of oleate binding to Cygb (Figure 2B) is not compatible with the results of the oleate titration, giving $K_{D}$ values of 110 and $0.7 \mu \mathrm{M}$ from the kinetics and titration data respectively. Thus the $k_{\text {on }}$ and $k_{\text {off }}$ values for oleate binding indicate that with $5 \mu \mathrm{M}$ of protein and 10 $\mu \mathrm{M}$ oleate, the occupancy of the lipid should be approximately $20 \%\left(k_{\text {on }}=0.9 \mathrm{~s}^{-1}, k_{\text {off }}=5 \mathrm{~s}^{-1}\right)$. However, with titration of Cygb with oleate clearly shows that over $80 \%$ of the protein is in the pentacoordinate conformation with a 1:2 protein to oleate ratio. Furthermore, although the kinetics predicts low occupancy the spectral changes seen in these stopped-flow experiments are typical of full occupancy and do not change on increasing the lipid concentration, indicating the protein is saturated (see Supplementary Figure S5). Clearly a single site mechanism of the form: 'Lipid + Cygb (hexacoordinate) $\leftrightarrow$ Complex (pentacoordinate)' is too simple and the data demands a more complex model of lipid binding and change in heme iron coordination. As Cygb is a homodimer, a possibility arises that the subunits act cooperatively as lipid bind. Thus the binding of a lipid to one subunit could drive both subunits into the pentacoordinate state, the second subunit binding lipid rapidly and with higher affinity. The kinetics would thus reflect the initial binding event but report the full optical transition. The second lipid binding would not be monitored in such transient experiment but would influence the equilibrium titration experiments, thus allowing a discrepancy in the value of $K_{D}$ between the measurements. Cygb cooperativity has previously been reported for oxygen binding to the ferrous protein, with both positive and negative cooperatively observed depending on temperature and $\mathrm{pH}[6]$. The titration curve from Figure $2 \mathrm{~A}$ can also be fitted to a cooperative 'concerted model' (with Hill coefficient of 1.4) of protein-ligand binding for a dimeric protein, with a low affinity tense or ' $T$ ' state and a high affinity relaxed or ' $R$ ' state of the concerted model [27]. The resulting residuals between the data and the fit are not significantly different to the fit using the fractional saturation binding curve (see Supplementary Figure S1). Therefore, cooperativity between the subunits of the dimer appears plausible.

Support for this proposal may be found in the structure of Cygb. Although the quaternary structure of Cygb in situ is currently unknown in the crystal Cygb exists as a cysteine-linked homodimer with each heme pocket facing opposite sides of the dimer surface [3]. In a double cysteine mutant of Cygb (Cys38Ser, Cys83Ser) the disulfide bridge linking the homodimer is absent. Under these conditions one subunit of the homodimer has the heme iron in a hexacoordinate state while the other subunit has partial heme pentacoordination, resulting from a shift of the E1-E10 segment [3]. A cysteine disulfide bridge (Cys 46, Cys 55) is also present in Ngb and has been found to influence the affinity of the iron atom for the distal histidine [32]. Reduction of the disulfide bond, or mutation of the cysteine residues leads to an increase the affinity of the iron atom for the distal histidine [32]. Thus removing the disulphide bridge appears to weaken the hexacoordinate nature of Cygb, but strengthen it in Ngb. It appears, therefore, that inter-subunit interactions influence the 
pentacoordinate-hexacoordinate equilibrium of the heme. This conclusion is in keeping with our proposal that binding of lipid to one subunit will affect the dissociation of the distal histidine from the iron in the other subunit, driving it HS, and enhance the binding of lipid to this second subunit.

Distinct to the Cygb family are extended N (1-17) and C (172-190) termini, both segments are highly disordered; hence these segments do not appear in the crystal structures. Neither of the two segments falls close to crystal contacts, indicating that their disorder should not be ascribed to crystal packing effects [3]. The function of these disordered end segments is currently unknown. However, in light that the protein appears to specifically bind lipids it is feasible that these segments may be involved in lipid binding.

\section{Effect of oleate on the acid/alkaline spectral transitions.}

The optical transitions observed in Cygb in response to changes in $\mathrm{pH}$ are shown in Figure $3 \mathrm{~A}$ (घ). Ferric Cygb in the absence of oleate shows multiple acid-alkaline transitions with four distinct optical species between pH 5 and pH 13 linked by three pK values. The highest pK value at 13.3 is accompanied by increase in absorbance at $390 \mathrm{~nm}$ and is assigned to heme release on protein denaturation. The lower two pK values represent optical changes between three distinct species, the spectra of which are shown in Figure 3B. The transition with a pK of 8.2 accompanied changes in the spectrum from 416, 532 and $543 \mathrm{~nm}$ at low pH to 413,565 and $578 \mathrm{~nm}$ at high pH with an additional band at $620 \mathrm{~nm}$. These changes are similar to that observed upon the addition of oleate (Figure 1) and are thus likely to also represent a LS to HS spin change in heme iron coordination. Therefore at physiological $\mathrm{pH}$ the ferric Cygb shows partial pentacoordination (14\%). A second acid-alkaline is observed with a pK of 11.0, accompanied by a shift of the Soret peak maximum to $418 \mathrm{~nm}$ and the disappearance of the $620 \mathrm{~nm}$ band in the more alkaline species (Figure 3B, dashed line). This high pH species is likely to be a hydroxide ligand bound to the heme iron, an acid-alkaline transition also observed in other pentacoordinate hemoglobins, although usually at lower $\mathrm{pH}$ values (human $\mathrm{Hb}$ $\mathrm{pK}=8.0$, horse $\mathrm{Mb} \mathrm{pK}=8.9$ (24)). Thus this transition for Cygb is far outside the normal physiological $\mathrm{pH}$ range. Thus from acid to alkali the three species are (i) His-Fe'"-His, (ii) $\mathrm{His}-\mathrm{Fe}^{\prime \prime \prime}-\mathrm{H}_{2} \mathrm{O}$, (iii) His-Fe' $\mathrm{OH}^{\circ}$.

The $\mathrm{pH}$ titration of ferric Cygb in the presence of two fold excess oleate is also shown in Figure 4A (O). In the presence of oleate, there is an acid-alkaline transition with a pK of 13.6 , indicative of protein denaturation. Additionally, a transition with pK of 10.6 can be seen, essentially identical to that observed in the absence of oleate. The most acidic transition, however, shows small changes in the optical spectra with a pK of 7.0, significantly different from the transition with pK of 8.2 observed in the absence of oleate. The optical spectra of the three optical species in the presence of oleate are shown in Figure 3C. The spectrum at pH 6.5 (Figure 3C, solid line) is considerably different to the acidic spectrum observed in the absence of oleate (Figure 3B, solid line), with a Soret peak at $409 \mathrm{~nm}$ and three peaks in the visible region at $535 \mathrm{~nm}, 568 \mathrm{~nm}$ and 620 $\mathrm{nm}$. The initial transition with $\mathrm{pK}$ of 7.0 shows only minor changes in the positions and intensity of the peaks ( $\mathrm{pH}$ 9.8, Figure $3 \mathrm{C}$, dotted line). Thus for the lipid bound Cygb, the distal histidine is already displaced; therefore the most acid form of the protein is already pentacoordinate. The small transition observed with $\mathrm{pK}$ of 7 may represent a slight disturbance of the optical spectrum due to a protonation of a group in the proximity of the iron, likely the distal histidine itself.

The evidence presented here suggests that the hexacoordinate conformation of Cygb can easily be disrupted in the ferric oxidation state, much more so than other similar hexacoordinate hemoglobins like $\mathrm{Ngb}$, despite their common ability to exchange the distal histidine for ligands such as $\mathrm{O}_{2}$ and $\mathrm{CO}$.

\section{Effect of oleate on the EPR spectrum of cytoglobin.}

The EPR spectrum of Cygb in the presence and absence of oleate is shown in Figure 4. Signals at $g=3.18$ and $g=2.05$ are observed, indicative of a LS heme iron. These are components of a previously reported LS signal of ferric Cygb $\left(g_{1}=1.20 g_{2}=2.06 g_{3}=3.20\right)$, and assigned to an LS3 signal 
typical of a HisF8-Fe'"-HisE7 coordination [33, 34]. Furthermore, a HS signal at g=5.87is present. This axial HS ferric heme signal is virtually identical to that observed in other globins, such as $\mathrm{Mb}$ and $\mathrm{Hb}$, and denotes a water molecule coordinated to the heme iron [30, 35, 36]. This HS signal has also previously been observed in ferric Cygb [34]. Addition of oleate at pH 7.4 decreases the LS signal, with a concurrent increase in the $g=5.87 \mathrm{HS}$ signal. Although this signal is broader than in the absence of oleate it is entirely consistent with water coordinated to the iron as suggested by the optical spectra (Fig 1).The LS form of the protein decreases from $70 \%$ to $25 \%$ on addition of oleate, showing addition of lipid destabilises the LS form of the protein, shifting the spin state equilibrium strongly towards the high spin state as concluded from the optical data.

Although in general agreement, the EPR and optical experiments show some quantitative discrepancies: the EPR spectra report more HS protein in the absence of and lesser in the presence of oleate than expected from the optical data. An explanation for these differences may be found in our observation that the colour of the protein is temperature dependent. At room temperature or when frozen at $>-10^{\circ} \mathrm{C}$ the protein solution at neutral $\mathrm{pH}$ is red typical of a bis his ferric heme protein. However, at temperatures of $-20^{\circ} \mathrm{C}$ or below, the frozen sample takes a brownish hue, typical of high spin, water coordinated, ferric heme. Thus it appears that low temperature alters the equilibrium between high- and low-spin forms, destabilising the LS form. Partial dissociation of the histidine from the iron on lowering the temperature is unexpected as such coordination is usually strengthened under these conditions. This indicates that the conformation of the protein must be poised in such a way that in lowering the temperature interactions elsewhere in the protein are strengthened, leading to a conformational transition that strains the Fe-His bond. In the presence of oleate such strain between the parts of the molecule is relieved. Under these conditions lowering the temperature favours Fe-His bond formation and stabilises the LS form. This can also be seen through colour changes on freezing.

A Cys38Ser Cys83Ser double mutation of Cygb completely removed the HS signal, stabilising the LS form of the protein [34]. Again, this supports the hypothesis that a degree of cooperativity exists between the protein dimers.

\section{Comparison between lipid induced spectral changes in Cytoglobin and Neuroglobin}

Neuroglobin (Ngb) is very similar to cytoglobin in that it contains a hexacoordinate heme and is present at low concentration in the cell and possible has signalling role for the oxidised form of the protein [37]. Thus we tested whether lipids such as oleate induced similar conformational changes in ferric Ngb. The spectral comparison between Cygb and Ngb on oleate addition is shown in Figure 5 and Figure 6 . As seen in Figure 1, the addition of the oleate at stoichiometric concentrations induces the conformational change of Cygb, showing an appearance of a peak at 620 $\mathrm{nm}$ (Figure 5A and 5B). The addition of oleate to $\mathrm{Ngb}$ at these concentrations does not induce any significant optical changes and therefore does not induce any changes in the iron coordination of the heme moiety. At concentrations of oleate in large excess the gradual appearance of a band at 640 $\mathrm{nm}$ can be observed (Figure 5C and 5D). This implies that the heme iron is also transformed from hexacoordinate to high spin pentacoordinate, however, the effect is only observed at very high oleate concentrations and the process is not complete even at concentrations of $1 \mathrm{mM}$ oleate, 200 fold excess in relation to the protein concentration. This transformation is also observed with Cygb, with a loss of the $620 \mathrm{~nm}$ band formed at low oleate concentration, and the appearance of a $640 \mathrm{~nm}$ band at high oleate concentration, identical to that observed in Ngb. (Figure 5A and 5B). These optical changes are accompanied with a major change in the Soret spectrum with a partial hypsochromic shift to a band $378 \mathrm{~nm}$, indicative of the heme in free solution. Thus at high oleate concentrations, both proteins are partially denatured by the excess lipid, although Cygb seems to be more resistant to denaturation by lipids compared to Ngb (Figure 6).

\section{Lipid Oxidation}


$\mathrm{Mb}$ is known to participate in lipid oxidation (peroxidation) reactions that can be detected in vivo under some disease conditions such as acute renal failure following rhabdomyolysis [18, 38, 39]. Thus $\mathrm{Mb}$ is a useful protein with which to compare Cygb in regard to the capacity to catalyze lipid oxidation reactions. Figure 7 and Figure 8 show the oxidation of lecithin liposomes catalyzed by ferric $\mathrm{Mb}$ and ferric $\mathrm{Cygb}$ at $\mathrm{pH}$ 7.4. The optical changes for the reaction of both $\mathrm{Cygb}$ and $\mathrm{Mb}$ with liposomes show an increase in the absorbance at $234 \mathrm{~nm}$, signifying the oxidation of the liposome lipids (Figure 7). The increase in absorbance is driven by the free radical mediated oxidation of lipids, causing the re-arrangement of dienes, such as the 1,4 cis-cis pentadiene systems found in arachidonate and linoleate, to a 1,3 cis-trans conjugated diene, showing absorbance maxima at 234 $\mathrm{nm}$ or a 1,3 conjugated diene further conjugated to another diene or keto group showing absorbance maxima at $280 \mathrm{~nm}[40,41]$. Free radical damage can also result in the depletion of conjugated diene as shown previously [41]. However, under these experimental conditions the extent of conjugated diene formation outweighs the extent of conjugated diene destruction and hence can be used to follow lipid oxidation but should not be used to quantify the overall extent of lipid oxidation. Accompanying the increase in conjugated dienes are optical changes of the Cygb Soret heme spectrum, which shows a decrease in absorbance associated with heme bleaching from redox-mediated free radical damage (Figure 7B). The Soret peak following addition of Cygb to the liposomes is at $412 \mathrm{~nm}$, not at $416 \mathrm{~nm}$. This shows that the normal low-spin hexacoordinate ferric protein is not present immediately after addition of the protein to the liposomes, with the Cygb spectrum resembling the optical spectrum of Cygb following oleate addition.

$\mathrm{Mb}$ catalysed oxidation of liposomes is shown in Figure $7 \mathrm{C}$ and 7D. Unlike Cygb, however, the optical changes in the Soret spectrum of the Mb heme shows both increases in intensity at 425 $\mathrm{nm}$ as well as decreases in heme intensity at $408 \mathrm{~nm}$, with an isosbestic point at $420 \mathrm{~nm}$. These optical changes are indicative of the formation of ferryl $\mathrm{Mb}$ from ferric $\mathrm{Mb}$, with no appreciable loss of heme optical intensity due to $\mathrm{Mb}$ degradation.

Following a lag period both $\mathrm{Mb}$ and $\mathrm{Cygb}$ induce a cascade of lipid oxidation. The lag periods were $7.6 \mathrm{~min}$ and $42.2 \mathrm{~min}$ for Cygb and $\mathrm{Mb}$ respectively (Figure 8A). During the lag period, small amounts of lipid peroxides, present in the liposome preparation, react with the heme protein to generate ferryl heme iron. This ferryl in turn reacts with lipids to cause free radical damage and the generation of lipid oxidation products, including more lipid peroxides. The level of heme protein redox cycling eventually generates a critical level of lipid-based radicals which causes the cascade of lipid oxidation, shown by the rapid increase in the signal at $234 \mathrm{~nm}$. Cygb is much more pro-oxidant leading to a cascade of lipid oxidation 5 fold quicker than Mb. Ngb showed no appreciable lipid oxidation reaction during the time course of the reaction beyond autoxidation of the lipids in an aerobic buffer (Figure 8). Measurement of the maximum rate of lipid oxidation can also be used as a measure of the pro-oxidant capacity of the proteins. The maximum rate of conjugated diene formation for $\mathrm{Cygb}, \mathrm{Mb}$ and $\mathrm{Ngb}$ are shown in Figure 8B. Cygb oxidises lipids during the cascade 5 fold faster compared with $\mathrm{Mb}$, with rates of conjugated diene formation reaching a maximum of $26.7 \mathrm{nM} \mathrm{s}^{-1}$ and $134.3 \mathrm{nM} \mathrm{s}^{-1}$ for $\mathrm{Mb}$ and Cygb respectively. The extent of conjugated diene formation with $\mathrm{Mb}$ was greater than with Cygb; $65.1 \mu \mathrm{M}$ for $\mathrm{Mb}$ and $55.3 \mu \mathrm{M}$ for Cygb after lipid oxidation was complete. This does not necessarily mean that more lipids were oxidised by $\mathrm{Mb}$ as conjugated diene formation does not represent an unambiguous quantitative measure of overall lipid oxidation. Bleaching of Cygb could result in incomplete oxidation of lipid; however, addition of 3 $\mu \mathrm{M}$ Cygb to liposomes instead of $1 \mu \mathrm{M}$ did not change the overall extent of conjugated diene formation, indicating that lipid oxidation was complete with the lower concentration of Cygb (data not shown).

\section{Conclusions.}

The data presented shows that the addition of lipids to Cygb in the ferric oxidation state, but not the ferrous state, induces optical changes that are consistent with a protein conformational change resulting in a transition of the heme iron from hexacoordinate to pentacoordinate. This lipid- 
induced transformation occurs with a range of lipids and does not occur under comparable conditions to similar hexacoordinate hemoglobins such as Ngb. Therefore, this lipid-induced transformation of Cygb iron coordination may be a unique property of this hemoglobin and thus may be related to its physiological function. The capacity of Cygb to induce lipid oxidation reactions in vitro, together with the lipid binding data, leads us to propose that the interaction of Cygb with lipids explains their potent pseudo-peroxidase activity and is likely to play an important role in the physiological function of the protein. Our data shows that Cygb is more potent at generating lipid oxidation products compared to Mb. As Ngb appears to have little capacity to oxidise lipid, this suggests that the physiological functions of Cygb and Ngb are very different. This high level of Cygb pro-oxidant activity at first appears to contradict many studies that have proposed that Cygb functions to protect the cell against oxidative stress and reactive oxygen species. However, with the low concentration of the protein in cells, together with the degradation of the heme under advanced redox activity means that this pathway of lipid oxidation is unlikely to cause extensive cellular damage. This mechanism is similar to that proposed by Kagan et al. with the interaction of cytochrome $c$ and cardiolipin [42]. Here lipid oxidation is catalyzed by a peroxidase activity of cardiolipin-bound cytochrome c, inducing pro-apoptotic pathways. Modified lipids formed by the redox activity of cytochrome $c$, as well as other hemoglobins, are known potent cell signalling molecules. Free radical catalyzed lipid oxidation is known to induce the generation of biologically active molecules such as the vasoactive isoprostanes, which participate as pathophysiological mediators in oxidant injury [43], or electrophilic lipids, reacting with thiols and cysteines residues that affect various cell signalling pathways $[20,22]$. Thus under an oxidative environment, Cygb will be oxidised to the ferric form, allowing interaction between the protein and lipid to form biologically active cell signalling molecules that may induce cell signalling pathways and an antioxidant response to the oxidative environment.

\section{Acknowledgements:}

We thank Badri Rajagopal and Jonathan Worrall for their kind donation of neuroglobin and Tom Brittain (University of Auckland, New Zealand) for the kind donation of the plasmid containing the neuroglobin gene.

Funding.

This work was funded by the BBSRC (Grant number BBF0076631).

\section{References.}

1 Burmester, T., Ebner, B., Weich, B. and Hankeln, T. (2002) Cytoglobin: a novel globin type ubiquitously expressed in vertebrate tissues. Mol. Biol. Evol. 19, 416-421

2 Fordel, E., Geuens, E., Dewilde, S., De Coen, W. and Moens, L. (2004) Hypoxia/ischemia and the regulation of neuroglobin and cytoglobin expression. IUBMB Life 56, 681-687

3 de Sanctis, D., Dewilde, S., Pesce, A., Moens, L., Ascenzi, P., Hankeln, T., Burmester, T. and Bolognesi, M. (2004) Crystal structure of cytoglobin: the fourth globin type discovered in man displays heme hexa-coordination. J. Mol. Biol. 336, 917-927

4 Burmester, T., Weich, B., Reinhardt, S. and Hankeln, T. (2000) A vertebrate globin expressed in the brain. Nature 407, 520-523

5 Hargrove, M. S., Brucker, E. A., Stec, B., Sarath, G., Arredondo-Peter, R., Klucas, R. V., Olson, J. S. and Phillips, G. N., Jr. (2000) Crystal structure of a nonsymbiotic plant hemoglobin. Structure 8, 1005-1014

6 Fago, A., Hundahl, C., Dewilde, S., Gilany, K., Moens, L. and Weber, R. E. (2004) Allosteric regulation and temperature dependence of oxygen binding in human neuroglobin and cytoglobin. Molecular mechanisms and physiological significance. J. Biol. Chem. 279, 4441744426 
Kawada, N., Kristensen, D. B., Asahina, K., Nakatani, K., Minamiyama, Y., Seki, S. and Yoshizato, K. (2001) Characterization of a stellate cell activation-associated protein (STAP) with peroxidase activity found in rat hepatic stellate cells. J. Biol. Chem. 276, 25318-25323 Sawai, H., Kawada, N., Yoshizato, K., Nakajima, H., Aono, S. and Shiro, Y. (2003) Characterization of the heme environmental structure of cytoglobin, a fourth globin in humans. Biochemistry 42, 5133-5142

9 Schmidt, M., Gerlach, F., Avivi, A., Laufs, T., Wystub, S., Simpson, J. C., Nevo, E., SaaalerReinhardt, S., Reuss, S., Hankeln, T. and Burmester, T. (2004) Cytoglobin is a respiratory protein in connective tissue and neurons, which is up-regulated by hypoxia. J. Biol. Chem. 279, 8063-8069

10 Halligan, K. E., Jourd'heuil, F. L. and Jourd'heuil, D. (2009) Cytoglobin is expressed in the vasculature and regulates cell respiration and proliferation via nitric oxide dioxygenation. J. Biol. Chem. 284, 8539-8547

11 Li, D., Chen, X. Q., Li, W. J., Yang, Y. H., Wang, J. Z. and Yu, A. C. (2007) Cytoglobin upregulated by hydrogen peroxide plays a protective role in oxidative stress. Neurochem. Res. 32, $1375-1380$

12 Lv, Y., Wang, Q., Diao, Y. and Xu, R. (2008) Cytoglobin: a novel potential gene medicine for fibrosis and cancer therapy. Curr. Gene Ther. 8, 287-294

13 Ostojic, J., Grozdanic, S., Syed, N. A., Hargrove, M. S., Trent, J. T., 3rd, Kuehn, M. H., Kardon, R. H., Kwon, Y. H. and Sakaguchi, D. S. (2008) Neuroglobin and cytoglobin distribution in the anterior eye segment: a comparative immunohistochemical study. J. Histochem. Cytochem. $56,863-872$

14 Nakatani, K., Okuyama, H., Shimahara, Y., Saeki, S., Kim, D. H., Nakajima, Y., Seki, S., Kawada, N. and Yoshizato, K. (2004) Cytoglobin/STAP, its unique localization in splanchnic fibroblastlike cells and function in organ fibrogenesis. Lab. Invest. 84, 91-101

15 Shaw, R. J., Omar, M. M., Rokadiya, S., Kogera, F. A., Lowe, D., Hall, G. L., Woolgar, J. A., Homer, J., Liloglou, T., Field, J. K. and Risk, J. M. (2009) Cytoglobin is upregulated by tumour hypoxia and silenced by promoter hypermethylation in head and neck cancer. Br. J. Cancer 101, 139-144

16 Huber, J., Bochkov, V. N., Binder, B. R. and Leitinger, N. (2003) The isoprostane 8-iso-PGE2 stimulates endothelial cells to bind monocytes via cyclic AMP- and p38 MAP kinasedependent signaling pathways. Antioxid. Redox. Signal. 5, 163-169

17 Kunapuli, P., Lawson, J. A., Rokach, J. A., Meinkoth, J. L. and FitzGerald, G. A. (1998) Prostaglandin F2alpha (PGF2alpha) and the isoprostane, 8, 12-iso-isoprostane F2alpha-III, induce cardiomyocyte hypertrophy. Differential activation of downstream signaling pathways. J. Biol. Chem. 273, 22442-22452

18 Moore, K. P., Holt, S. G., Patel, R. P., Svistunenko, D. A., Zackert, W., Goodier, D., Reeder, B. J., Clozel, M., Anand, R., Cooper, C. E., Morrow, J. D., Wilson, M. T., Darley-Usmar, V. and Roberts, L. J., 2nd (1998) A causative role for redox cycling of myoglobin and its inhibition by alkalinization in the pathogenesis and treatment of rhabdomyolysis- induced renal failure. J. Biol. Chem. 273, 31731-31737

19 Morrow, J. D., Minton, T. A. and Roberts, L. J., 2nd (1992) The F2-isoprostane, 8-epiprostaglandin F2 alpha, a potent agonist of the vascular thromboxane/endoperoxide receptor, is a platelet thromboxane/endoperoxide receptor antagonist. Prostaglandins 44, 155-163

20 Ceaser, E. K., Moellering, D. R., Shiva, S., Ramachandran, A., Landar, A., Venkartraman, A., Crawford, J., Patel, R., Dickinson, D. A., Ulasova, E., Ji, S. and Darley-Usmar, V. M. (2004) Mechanisms of signal transduction mediated by oxidized lipids: the role of the electrophileresponsive proteome. Biochem. Soc. Trans. 32, 151-155

21 Diers, A. R., Higdon, A. N., Ricart, K. C., Johnson, M. S., Agarwal, A., Kalyanaraman, B., Landar, A. and Darley-Usmar, V. M. (2010) Mitochondrial targeting of the electrophilic lipid 
15-deoxy-Delta12,14-prostaglandin J2 increases apoptotic efficacy via redox cell signalling mechanisms. Biochem. J. 426, 31-41 Levonen, A. L., Landar, A., Ramachandran, A., Ceaser, E. K., Dickinson, D. A., Zanoni, G., Morrow, J. D. and Darley-Usmar, V. M. (2004) Cellular mechanisms of redox cell signalling: role of cysteine modification in controlling antioxidant defences in response to electrophilic lipid oxidation products. Biochem. J. 378, 373-382

23 Murphy, M. P. (2006) Induction of mitochondrial ROS production by electrophilic lipids: a new pathway of redox signaling? Am. J. Physiol. Heart Circ. Physiol. 290, H1754-1755

24 Trent, J. T., 3rd and Hargrove, M. S. (2002) A ubiquitously expressed human hexacoordinate hemoglobin. J. Biol. Chem.277, 19538-19545

25 Reeder, B. J. and Wilson, M. T. (2005) Desferrioxamine Inhibits Production of Cytotoxic Heme to Protein Cross-Linked Myoglobin: A Mechanism to Protect against Oxidative Stress without Iron Chelation. Chem. Res. Toxicol. 18, 1004-1011

26 Egmond, M. R., Brunori, M. and Fasella, P. M. (1976) The steady-state kinetics of the oxygenation of linoleic acid catalysed by soybean lipoxygenase. Eur. J. Biochem. 61, 93-100

27 Monod, J., Wyman, J. and Changeux, J. P. (1965) On the Nature of Allosteric Transitions: a Plausible Model. J. Mol. Biol. 12, 88-118

28 Reeder, B. J., Grey, M., Silaghi-Dumitrescu, R. L., Svistunenko, D. A., Bulow, L., Cooper, C. E. and Wilson, M. T. (2008) Tyrosine residues as redox cofactors in human hemoglobin: implications for engineering nontoxic blood substitutes. J. Biol. Chem. 283, 30780-30787

29 Weil, J. A., Bolton, J. R. and Wertz, J. E. (1994) Electron paramagnetic resonance: Elementary theory and practical applications. John Wiley \& Sons, Inc. New York

30 Svistunenko, D. A., Sharpe, M. A., Nicholls, P., Blenkinsop, C., Davies, N. A., Dunne, J., Wilson, M. T. and Cooper, C. E. (2000) The pH dependence of naturally occurring low-spin forms of methaemoglobin and metmyoglobin: an EPR study. Biochem. J. 351 Pt 3, 595-605

31 Antonini, E. and Brunori, M. (1971) Hemoglobin and myoglobin and their reaction with ligands. In Frontiers in Biology (Neuberger, A. and Tatum, E. L., eds.), pp. 13-52, NorthHolland publishing company, Amsterdam-London

32 Hamdane, D., Kiger, L., Dewilde, S., Uzan, J., Burmester, T., Hankeln, T., Moens, L. and Marden, M. C. (2005) Hyperthermal stability of neuroglobin and cytoglobin. Febs J. 272, 2076-2084

33 Van Doorslaer, S., Vinck, E., Trandafir, F., loanitescu, I., Dewilde, S. and Moens, L. (2004) Tracing the structure-function relationship of neuroglobin and cytoglobin using resonance Raman and electron paramagnetic resonance spectroscopy. IUBMB Life 56, 665-670 Vinck, E., Van Doorslaer, S., Dewilde, S. and Moens, L. (2004) Structural change of the heme pocket due to disulfide bridge formation is significantly larger for neuroglobin than for cytoglobin. J. Am. Chem. Soc. 126, 4516-4517 structure of protoheme proteins. 3. Configuration of the heme and its ligands. J. Biol. Chem. 243, 1871-1880

36 Peisach, J., Blumberg, W. E., Wittenberg, B. A., Wittenberg, J. B. and Kampa, L. (1969) Hemoglobin A: an electron paramagnetic resonance study of the effects of interchain contacts on the heme symmetry of high-spin and low-spin derivatives of ferric alpha chains. Proc. Natl. Acad. Sci. U S A 63, 934-939 Wakasugi, K., Nakano, T. and Morishima, I. (2003) Oxidized human neuroglobin acts as a heterotrimeric Galpha protein guanine nucleotide dissociation inhibitor. J. Biol. Chem. 278, 36505-36512

38 Holt, S., Reeder, B., Wilson, M., Harvey, S., Morrow, J. D., Roberts, L. J., 2nd and Moore, K. (1999) Increased lipid peroxidation in patients with rhabdomyolysis. Lancet 353, 1241 

of myoglobin and haemoglobin: oxidative stress in patients with rhabdomyolysis and subarachnoid haemorrhage. Biochem. Soc. Trans. 30, 745-748 Niu, Q. J. and Mendenhall, G. D. (1992) Yields of Singlet Molecular Oxygen from Peroxyl Radical Termination. J. Am. Chem. Soc. 114, 165-172

41 Reeder, B. J. and Wilson, M. T. (1998) Mechanism of reaction of myoglobin with the lipid hydroperoxide hydroperoxyoctadecadienoic acid. Biochem. J. 330, 1317-1323

42 Kagan, V. E., Tyurin, V. A., Jiang, J., Tyurina, Y. Y., Ritov, V. B., Amoscato, A. A., Osipov, A. N., Belikova, N. A., Kapralov, A. A., Kini, V., Vlasova, II, Zhao, Q., Zou, M., Di, P., Svistunenko, D. A., Kurnikov, I. V. and Borisenko, G. G. (2005) Cytochrome $c$ acts as a cardiolipin oxygenase required for release of proapoptotic factors. Nat. Chem. Biol. 1, 223-232

Morrow, J. D., Hill, K. E., Burk, R. F., Nammour, T. M., Badr, K. F. and Roberts, L. J. d. (1990) A series of prostaglandin F2-like compounds are produced in vivo in humans by a non-

cyclooxygenase, free radical-catalyzed mechanism. Proc. Natl. Acad. Sci. U S A 87, 9383-9387

\section{Figure Legends.}

Figure 1. Lipid-induced optical changes to cytoglobin

(A) Sodium oleate solution was added to ferric cytoglobin (5 $\mu \mathrm{M})$ in $0.5 \mu \mathrm{M}$ aliquots. (B) Difference spectra where the spectrum of ferric protein in the absence of oleate was removed from all subsequent spectra.

Figure 2. Oleate binding to cytoglobin.

(A) Ferric cytoglobin $(5 \mu \mathrm{M})$ was titrated with sodium oleate. After each addition of oleate the optical spectrum was recorded. Absorbance changes were adjusted to account for sample dilution and normalised. Solid line: data points fitted to equation 1 with a binding constant of $0.70( \pm 0.033)$ $\mu \mathrm{M}$ and a total protein concentration of $4.5( \pm 0.06) \mu \mathrm{M}$. (B) Oleate $(25-1000 \mu \mathrm{M})$ was added to ferric cytoglobin $(5 \mu \mathrm{M})$ in a rapid reaction stopped flow spectrophotometer. Kinetics of oleate binding was calculated from fitting the optical changes to a single exponential function. The $k_{\text {on }}$ was calculated as $4.53 \times 10^{4}\left( \pm 8.58 \times 10^{2}\right) \mathrm{M}^{-1} \mathrm{~s}^{-1}$ and the $k_{\text {off }}$ as $5.0( \pm 0.32) \mathrm{s}^{-1} . \mathrm{n}=3$.

Figure 3. Effect of oleate on the acid-alkaline transition of ferric cytoglobin.

Ferric cytoglobin $(5 \mu \mathrm{M})$ was adjusted to approximately $\mathrm{pH} 5.5$ by addition of buffer ( $10 \mathrm{mM}$ sodium phosphate, $20 \mathrm{mM}$ sodium tetraborate). Alkali (sodium hydroxide $0.05 \mathrm{M}-5 \mathrm{M}$ ) was titrated into the solution and the $\mathrm{pH}$ and optical spectra recorded. In the absence of oleate (A $\mathbf{\square})$, there are three distinct acid-alkaline phases with $\mathrm{pK}_{\mathrm{a}}$ values of $8.2( \pm 0.03), 10.9( \pm 0.08)$ and $>13$. In the presence of oleate $(\mathrm{A})$, there are two distinct acid-alkaline phases with $\mathrm{pK}_{\mathrm{a}}$ values of $10.7( \pm 0.03)$ and $>13$, with a small acid-alkaline phase at pH $7.0( \pm 0.02)$. (B and $\mathrm{C})$ Optical spectra at $\mathrm{pH} 6.0$ (solid line), $\mathrm{pH}$ 9.8 (dotted) and $\mathrm{pH} 12.0$ (dashed line) for protein in absence (B) and presence (C) of oleate. Spectra above $475 \mathrm{~nm}$ are multiplied by 10 .

Figure 4. EPR spectra of cytoglobin in the presence and absence of oleate. Cytoglobin $(80 \mu \mathrm{M})$ in 50 $\mathrm{mM}$ sodium phosphate buffer, $\mathrm{pH} 7.4$ was flash-frozen in dry ice-cooled methanol with (upper spectrum) or without (lower spectrum) sodium oleate $(160 \mu \mathrm{M})$. In the absence of oleate the protein is predominantly $(71.2 \%)$ in a HisF8-Fe' - -HisE7 coordination $\left(g_{3}=3.20, g_{2}=2.05, g_{1}\right.$ is of scale). In the presence of oleate the low-spin form is destabilised with and enhancement of the $g=5.87$ signal, assigned to high-spin water bound ferric heme iron.

Figure 5. Effect of low and high oleate concentration on the optical spectrum of ferric cytoglobin and neuroglobin. ( $A$ and $B$ ) Addition of oleate to cytoglobin initially induces a transformation from hexacoordinate to pentacoordinate as shown by the appearance of a peak at $620 \mathrm{~nm}$ (as seen in Figure 2). At higher oleate concentrations this peak is then shifted to $640 \mathrm{~nm}$ showing the eventual partial unfolding of the protein. For neuroglobin ( $C$ and $D$ ) the $620 \mathrm{~nm}$ band does not appear at 620 
$\mathrm{nm}$ with low concentrations of oleate, showing that there is little effect of oleate on the conformation of the protein. At high concentrations of oleate the protein eventually partially unfolds as observed by the appearance of the $640 \mathrm{~nm}$ peak.

Figure 6. Effect of oleate on the optical spectra of Cytoglobin and Neuroglobin.

Conditions are for those described in Figure 7. (A) Changes in Soret region (420 nm - $378 \mathrm{~nm}$ ) of

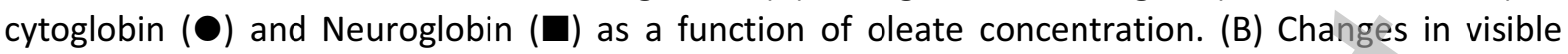
region $(620 \mathrm{~nm}-640 \mathrm{~nm})$ of cytoglobin $(\mathbf{O})$ and Neuroglobin $(\boldsymbol{\square})$ as a function of oleate concentration.

Figure 7. Oxidation of liposomes by Cytoglobin and Myoglobin.

Protein $(1 \mu \mathrm{M})$ was added to small unilamellar liposomes $(200 \mu \mathrm{g} / \mathrm{ml})$ in $25 \mathrm{mM}$ phosphate buffer $\mathrm{pH}$ 7.4 at $25{ }^{\circ} \mathrm{C}$. (A) Optical changes to liposomes following the addition of cytoglobin. (B) Optical changes from $(A)$ with the initial spectrum immediately following cytoglobin addition made silent. (C) Optical changes to liposomes following the addition of myoglobin. (D) Optical changes from (C) with the initial spectrum made silent. Time intervals between spectra were $1 \mathrm{~min}$, although only spectra every 4 min are shown.

Figure 8. Comparison of the lipid oxidation capability of myoglobin and cytoglobin.

Lipid oxidation was monitored optically at $234 \mathrm{~nm}$ and converted to conjugated diene concentration using a three-point baseline drop (see materials and methods). (A) Cytoglobin (solid line) shows a short lag period were lipid oxidation is slow followed by a cascade of lipid oxidation. Myoglobin (dotted line) shows a much longer lag period followed by a slow cascade phase of lipid oxidation. Neuroglobin (grey, dashed line) shows only small amounts of lipid oxidation within the time frame of the experiment. (B) The maximum rates of conjugated diene formation for myoglobin (Mb) and cytoglobin (Cygb) ( $n=6)$ and neuroglobin $(\mathrm{Ngb})(\mathrm{n}=3)$. 

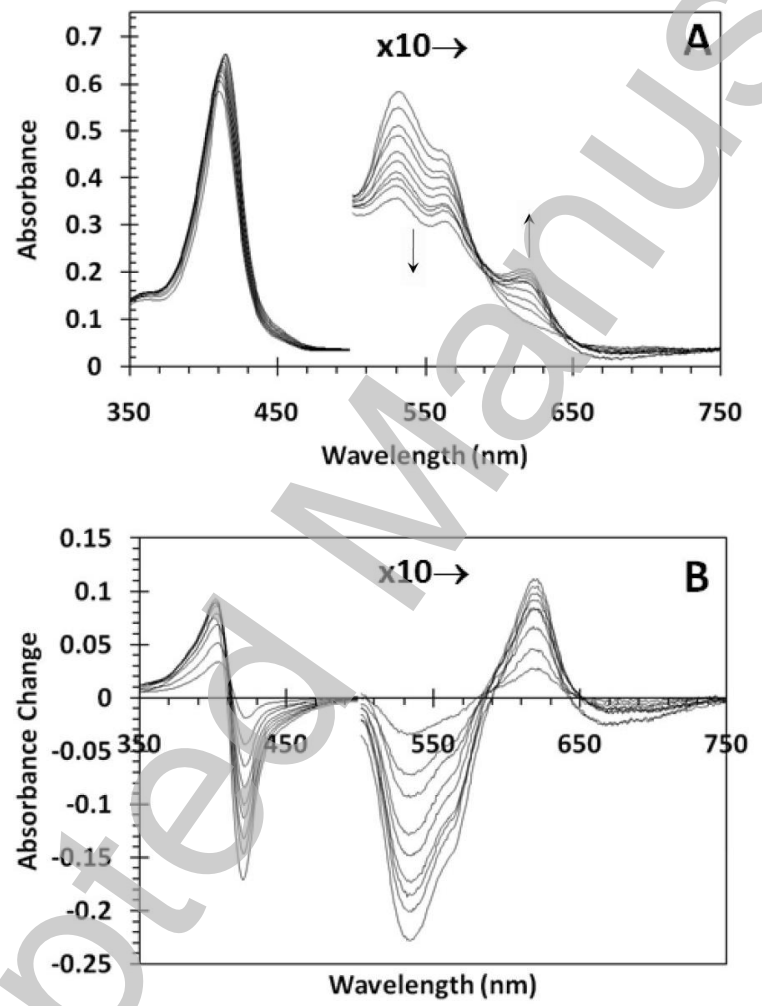

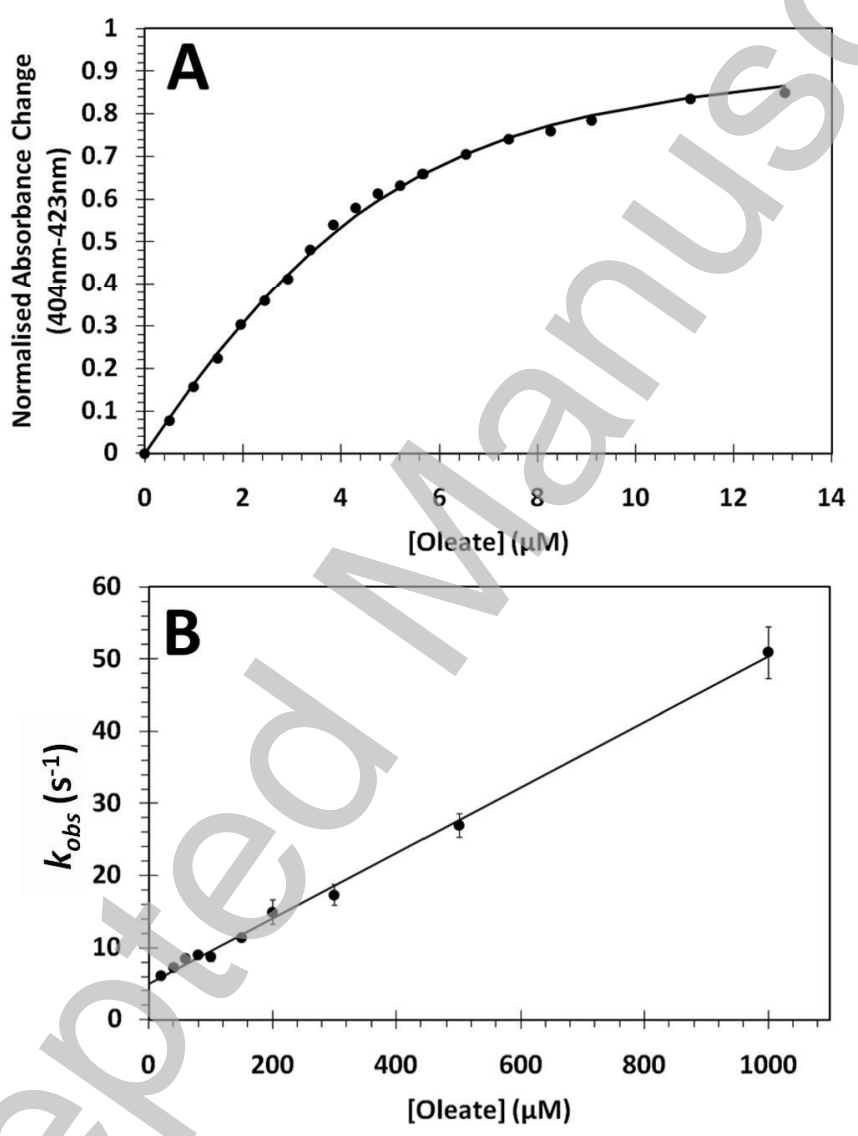

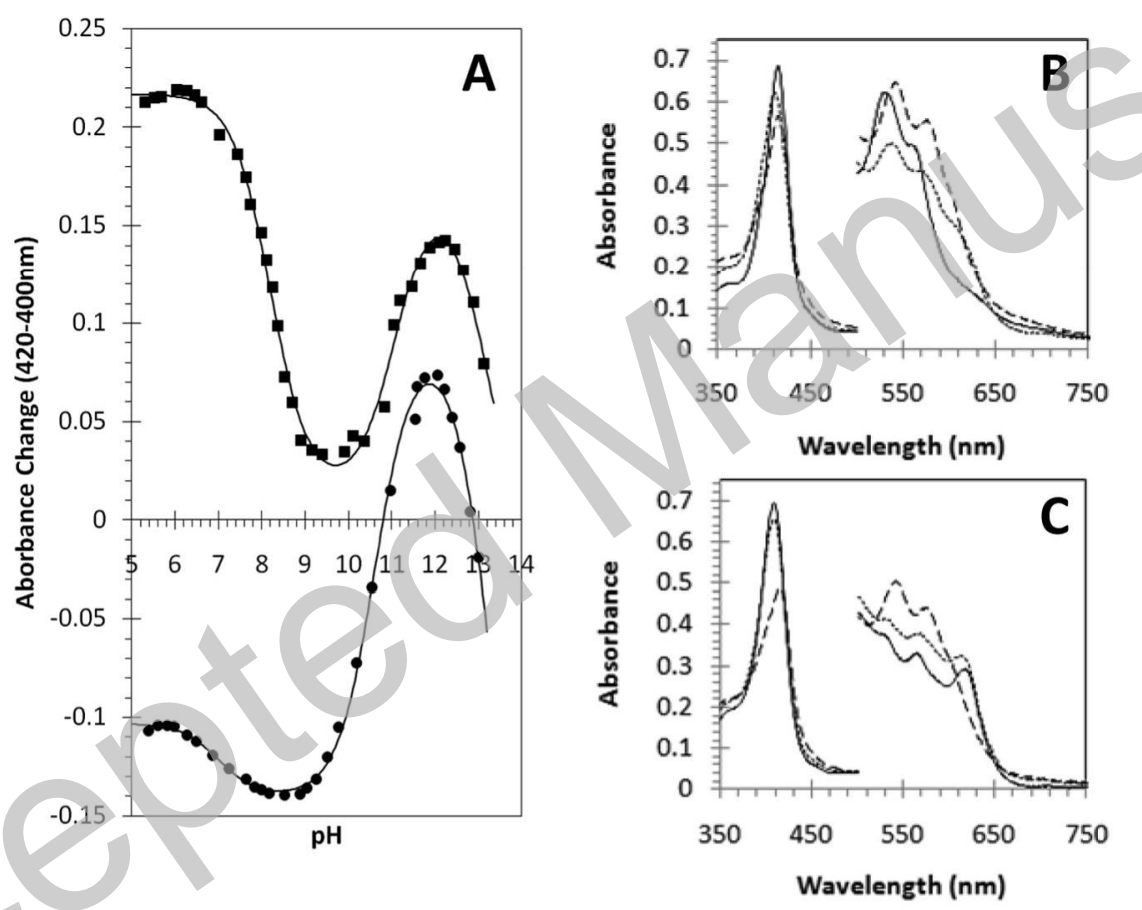


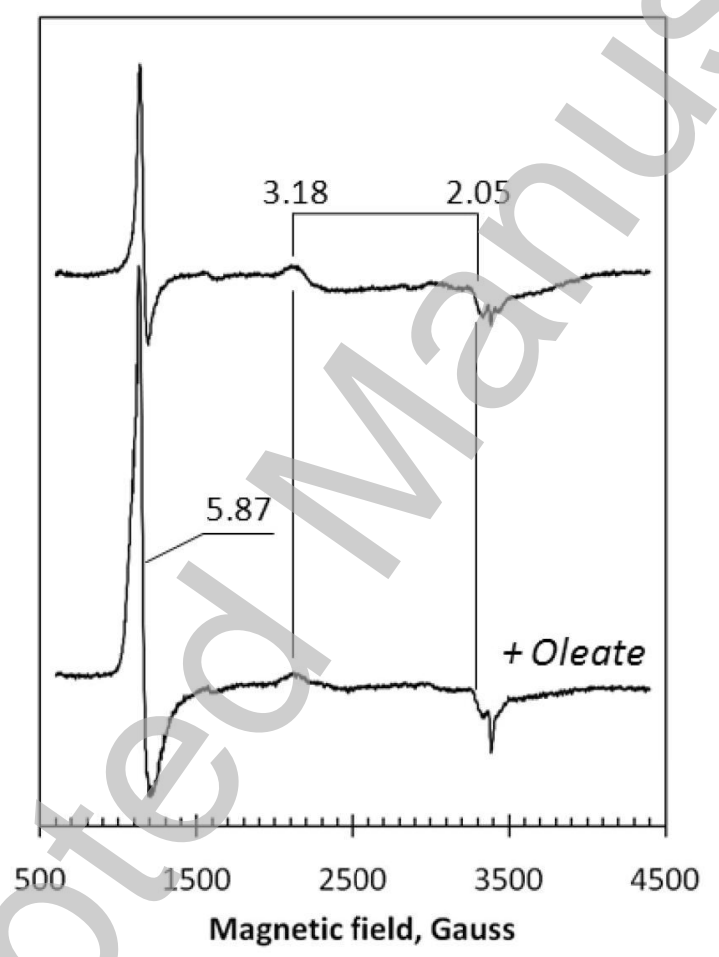



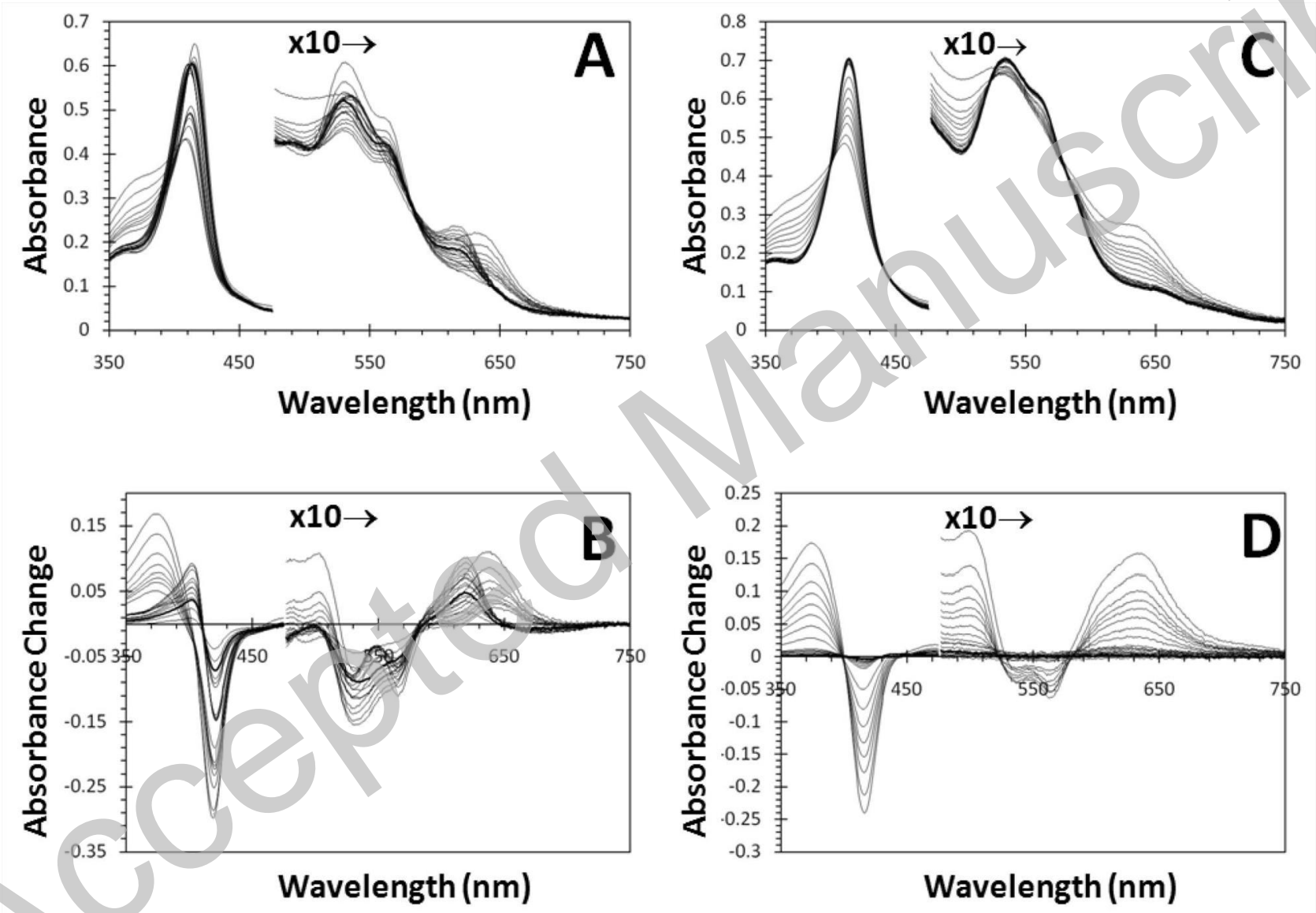

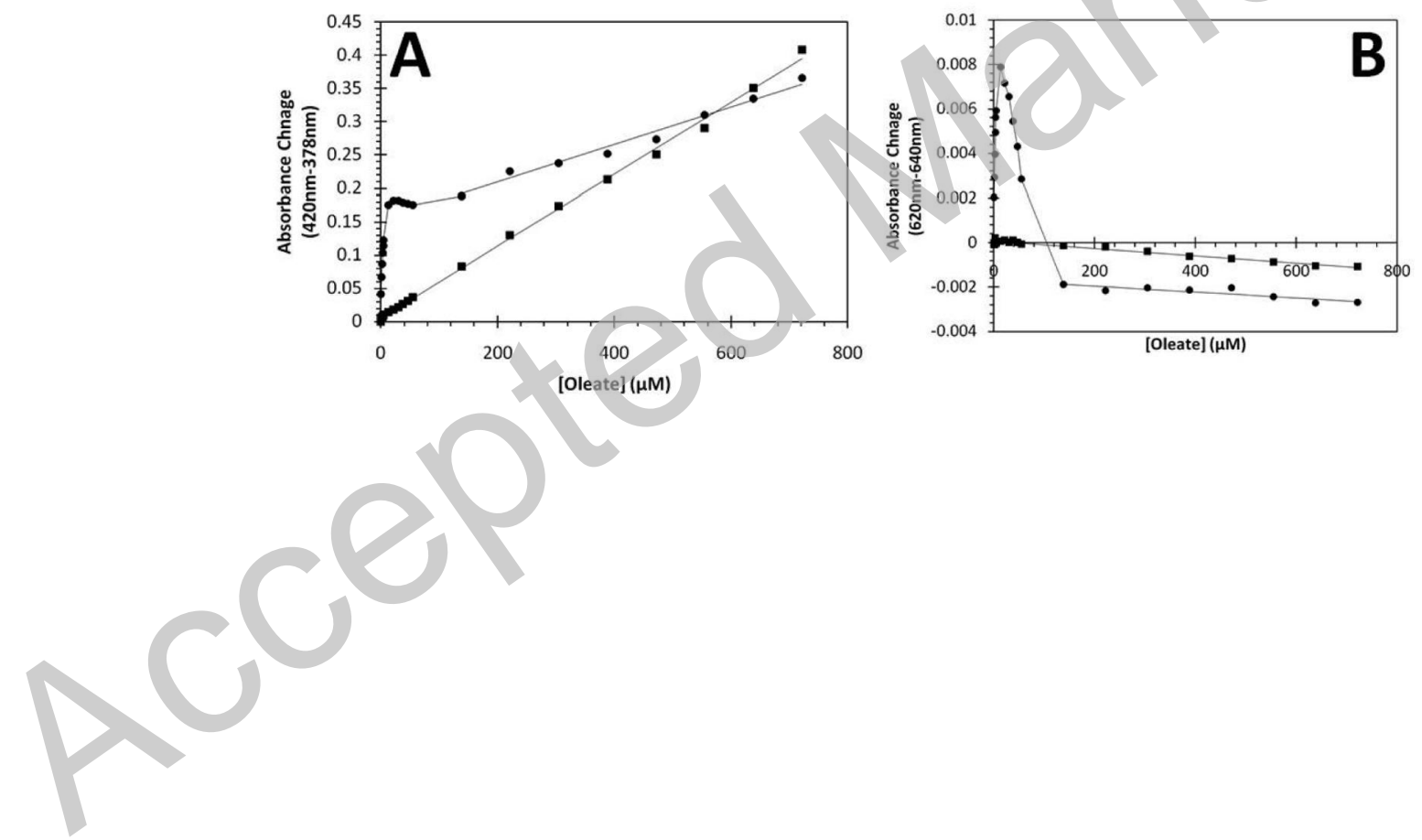

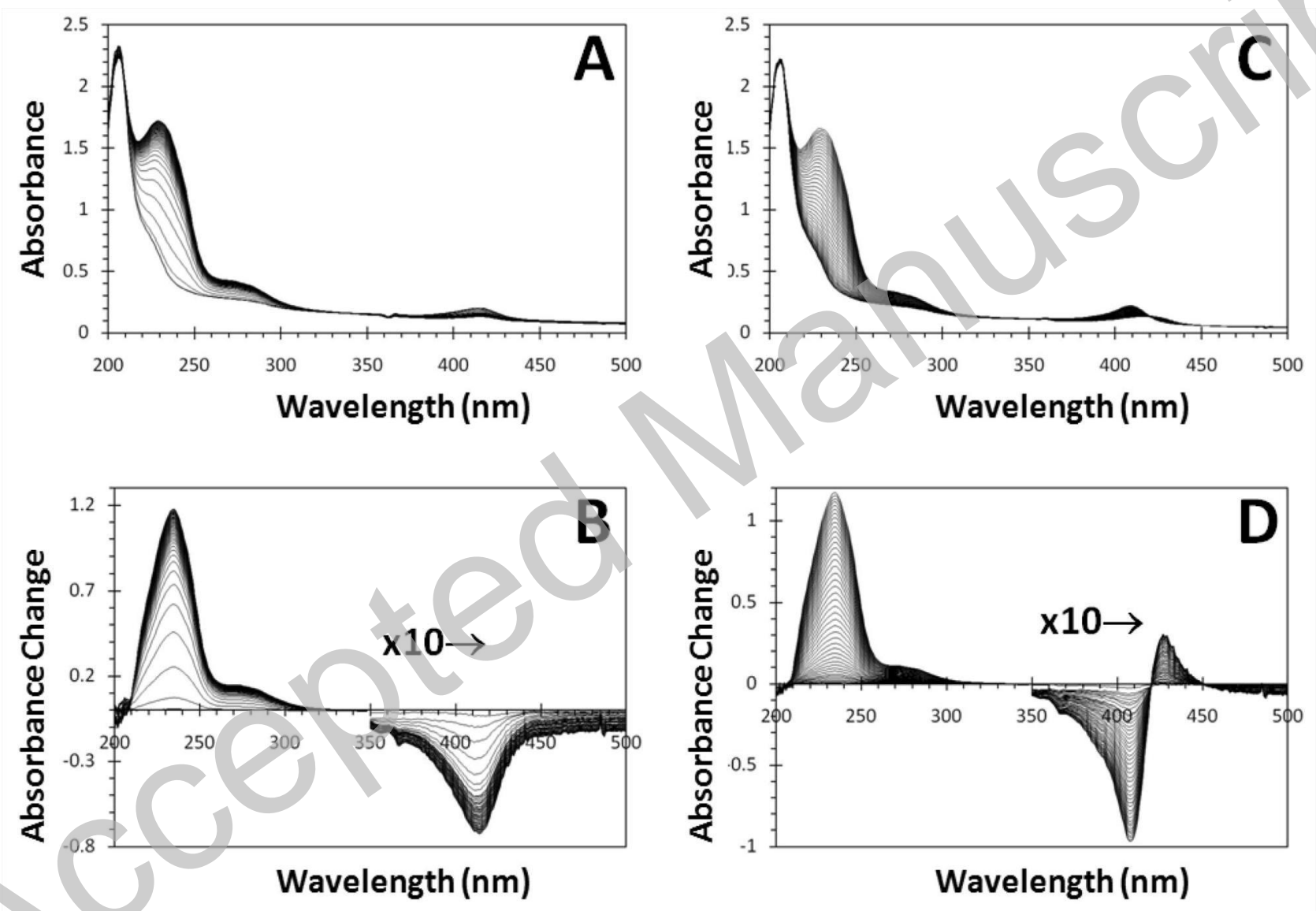

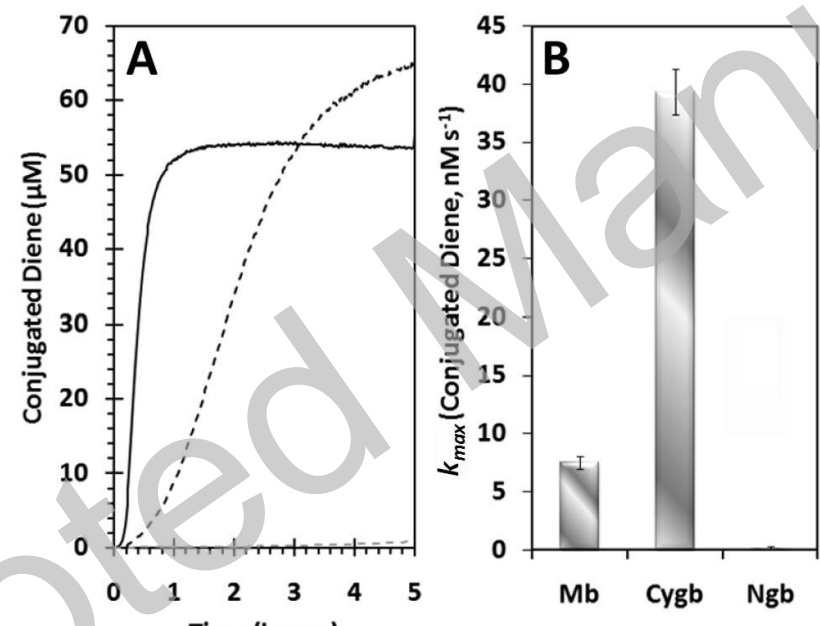

Licenced copy. Copying is not permitted, except with prior permission and as allowed by law. () 2010 The Authors Journal compilation @ 2010 Portland Press Limited 